\title{
Rhegmatogenous retinal detachment due to a macular hole in a patient with pars planitis: a case report
}

\author{
Panagiotis Stavrakas' \\ Angeliki A Androu' \\ Paris Tranos ${ }^{2}$ \\ Evgenia Kontou' \\ Maria Milia' \\ Ilias Georgalas ${ }^{3}$
}

'2nd Department of Ophthalmology, University of Athens Medical School, Attikon University General Hospital, Athens, Greece; ${ }^{2}$ Ophthalmica Clinic, Thessaloniki, Greece; ${ }^{3}$ Ist Department of Ophthalmology, G Genimatas General Hospital, Athens, Greece
Correspondence: Panagiotis E Stavrakas 2nd Department of Ophthalmology, University of Athens Medical School, Attikon University General Hospital, Rimini I, Chaidari, Attiki, 12462, Greece Email panos.stavrakas@yahoo.com
This article was published in the following Dove Press journal:

Therapeutics and Clinical Risk Management

30 December 2014

Number of times this article has been viewed

\begin{abstract}
We report a rare case of rhegmatogenous retinal detachment due to a full-thickness macular hole in a young patient with pars planitis. This study was an interventional case report. A 38-year-old Asian man presented with acute reduction of vision in his left eye. His past ocular history revealed a precedent of two intravitreal steroid injections in his left eye, and fundoscopy revealed a total bullous retinal detachment along with $360^{\circ}$ snowbanking at the pars plana. Precise preoperative visualization of the posterior pole was impossible due to a dense nuclear cataract. During surgery, an unexpected full-thickness macular hole with no associated epiretinal membrane was observed, which resulted in the retinal detachment. This case of chronic pars planitis complicated with a full-thickness macular hole resulting in retinal detachment was successfully treated with vitrectomy, internal limiting membrane peeling, and perfluoropropane tamponade. Visual acuity improved from hand movements to 6/36 Snellen at 12 months postsurgery. This case report illustrates the rare but possible association between pars planitis with macular hole formation and subsequent retinal detachment, underlying the beneficiary outcome of vitrectomy surgery both diagnostically and therapeutically.
\end{abstract}

Keywords: retinal detachment, macular hole, pars planitis, vitrectomy

\section{Introduction}

Pars planitis represents an idiopathic, insidious, chronic autoimmune reaction to elements of the peripheral retina, resulting in inflammation of the extreme retinal periphery, pars plana, and vitreous base. ${ }^{1}$ Pars plana exudates (snowbanks), vitritis with snowballs, and peripheral periphlebitis with perivascular sheathing represent common findings. The most common posterior segment complications include cystoid macular edema, epiretinal membrane formation, visually significant cataracts, neovascularization with or without associated vitreous hemorrhage, and retinal detachment. ${ }^{1}$

Development of a full-thickness macular hole secondary to pars planitis has only been reported twice in the literature. ${ }^{2,3}$ We report a case of a young patient with pars planitis diagnosed with rhegmatogenous retinal detachment due to a macular hole, who was treated with vitrectomy, internal limiting membrane peeling, and $\mathrm{C}_{3} \mathrm{~F}_{8}$ endotamponade.

\section{Case report}

A 38-year-old Asian man complained of an acute reduction of vision in his left eye. His past medical history was unremarkable, whereas his past ocular history revealed a precedent of two intravitreal steroid injections in his left eye. These injections were 
performed 5 years previously in his country of origin for treatment of cystoid macular edema. The patient was unable to provide any additional details regarding his visual acuity other than long-term decreased vision.

On examination, the best-corrected visual acuity was 6/36 Snellen and hand movements in the right and the left eye, respectively. Axial length in both eyes was similar ( $24.73 \mathrm{~mm}$ in the right eye and $24.69 \mathrm{~mm}$ in the left eye). Slit-lamp biomicroscopy revealed cells +1 in the anterior chamber and a dense nuclear and cortical cataract that significantly precluded fundoscopy. The latter revealed shallow inferior retinal detachment, snowballs, and with the aid of thorough scleral indentation, $360^{\circ}$ snowbanking was disclosed. No retinal breaks or holes were seen. Precise visualization of the posterior pole was impossible due to the density of the cataract.

Pertinent laboratory workup for conditions associated with intermediate uveitis, including hematology, serology, cutaneous, and enzyme tests, were negative. Imaging techniques, including a brain magnetic resonance imaging scan and a chest computed tomography and X-ray did not reveal any abnormal findings, and human leukocyte antigen typing for particular human leukocyte antigens was negative. The patient was referred to a uveitis specialist who confirmed the diagnosis of pars planitis. Two days later, the retinal detachment progressed to involve the entire retina, which acquired a bullous configuration with a negative "shifting fluid" that suggested a rhegmatogenous detachment and urgent surgery was scheduled.

The patient underwent a combined phacoemulsification and 23-gauge pars plana vitrectomy, which revealed an unexpected full-thickness macular hole with no associated epiretinal membrane formation, which resulted in the retinal detachment.

Additionally, the pars planitis clinical features were reestablished, including $360^{\circ}$ snowbanking (Figure 1A), as well as severe peripheral periphlebitis with vascular sheathing and mild vitritis with snowballs. Interestingly, there was a preexisting complete posterior vitreous detachment. A brilliant blue-assisted complete, atraumatic, wide internal limiting membrane peeling was performed and the retina was flattened through the macular hole (Figure 1B) using a $23 \mathrm{G}$ backflush cannula. $\mathrm{C}_{3} \mathrm{~F}_{8}(14 \%)$ was used as the endotamponade agent and $1 \mathrm{mg}$ of intravitreal triamcinolone $(1 \mathrm{mg})$ was injected in order to control inflammation. The patient was instructed to remain with prone posturing of the head for 5 days. Oral corticosteroid was prescribed to reduce postoperative inflammation, which was reduced slowly.
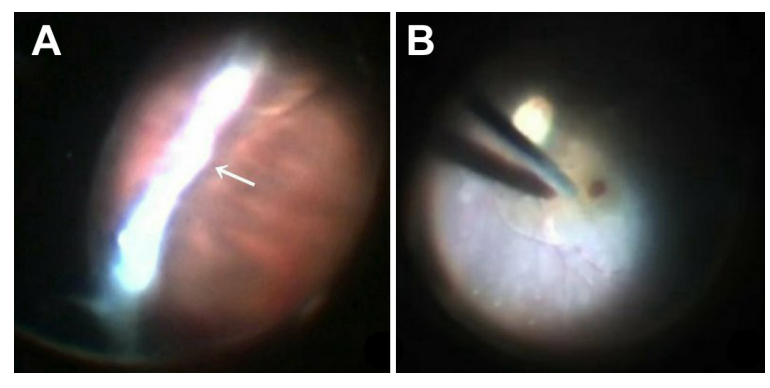

Figure I Intraoperative view of the extreme periphery showing severe snowbanking (arrow) (A) and of drainage of the subretinal fluid through the macular hole (B). Notes: Vasculitis along the inferior temporal vascular arcade can be seen.

Twelve months postoperatively, the full-thickness macular hole was closed, the retina remained attached (Figure 2), and the best-corrected visual acuity improved to $6 / 36$ Snellen. Pars planitis regressed and no additional therapy was needed. Fundoscopy and optical coherence tomography showed the persistence of a small quantity of triamcinolone trapped at the previously opened macular hole (Figure 3).

\section{Discussion}

Macular holes secondary to uveitis are known to occur rarely, and relatively few cases have been reported..$^{2-6}$ Full-thickness macular hole formation secondary to pars planitis has only been reported twice, ${ }^{2,3}$ and retinal detachment resulting from a postuveitic macular hole has been reported twice., ${ }^{4,5}$ Georgalas et $\mathrm{al}^{4}$ and Al-Dhibi et $\mathrm{al}^{5}$ described a rhegmatogenous retinal detachment due to a macular hole, but in those reports, the underlying pathology was Behçet's panuveitis, and silicone oil was used as endotamponade.

Because of the low incidence of this condition, the pathogenesis of a uveitic macular hole in the absence of associated epiretinal membrane formation and the most appropriate

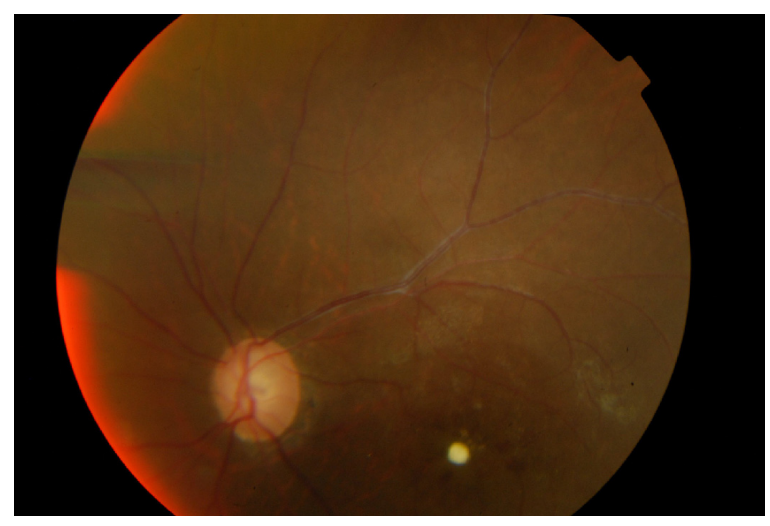

Figure 2 Twelve months postoperatively, the full-thickness macular hole was closed successfully and the retina remained attached.

Note: There are residual triamcinolone crystals at the macular hole. 


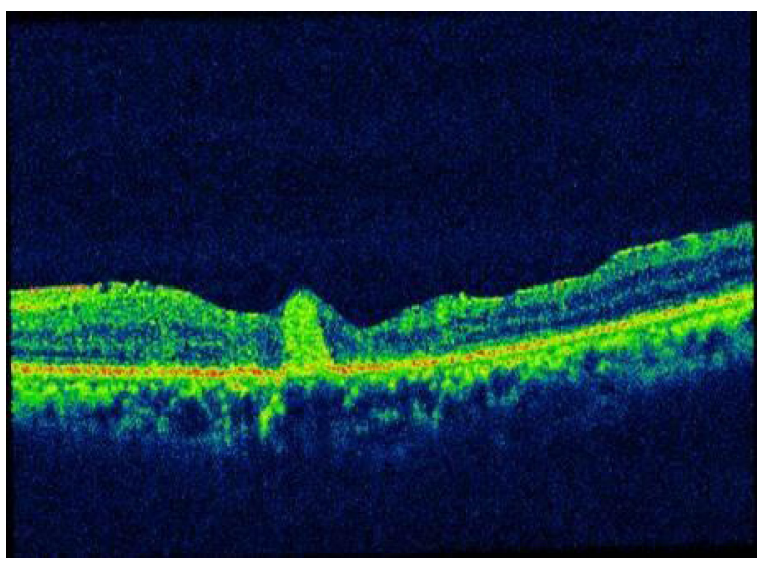

Figure 3 Optical coherence tomography image depicting residual triamcinolone at the macular hole.

therapeutic methods are yet to be established. In our case report, in the absence of previous optical coherence tomography data, we speculated that a macular hole resulted from longstanding cystoid macular edema, which progressed to a lamellar hole and subsequently to a full-thickness hole, and the traction caused by severe recurrent vitritis led to the development of retinal detachment. A causal relationship between pars planitis and cystoid macular edema leading to macular hole formation in a young patient, in the absence of epiretinal membrane formation, posterior staphyloma, or a history of trauma, can be reasonably supported in this case.

We excluded the possibility of "simple" macular hole retinal detachment because of the young age of the patient, the normal axial length, as well as due to the patient's past history of intraocular inflammation with a gradual decrease of visual acuity, and intravitreal steroid injections. Vitrectomy and complete internal limiting membrane peeling with gas tamponade was successful in closing the hole without the need for silicone oil, ${ }^{4,5}$ despite the possible higher risk of redetachment due to the longstanding intraocular inflammation.

The role of intravitreal triamcinolone as an adjunct treatment in this case remains unclear and controversial.
It may have offered the advantage of good control over the inflammation without any intraocular pressure complications. There have been previous reports on intravitreally injected residual triamcinolone at the macular hole, indicating that it does not affect final visual quality. ${ }^{7}$ However, the entrapment of triamcinolone material at the macular area in our case may have ultimately prevented further visual improvement because of its quantity, as shown in the fundus pictures and optical coherence tomography image (Figures 2 and 3). Subtenon triamcinolone may have been more advantageous over intravitreal injection, and we therefore do not recommend its use in gas-filled eyes.

\section{Conclusion}

This case report illustrates the rare but possible association between pars planitis with macular hole formation and subsequent retinal detachment underlying the beneficiary outcome of vitrectomy surgery both diagnostically and therapeutically in patients with complicated chronic intermediate uveitis.

\section{Disclosure}

The authors report no conflicts of interest in this work.

\section{References}

1. Malinowski SM, Pulido JS, Folk JC. Long-term visual outcome and complications associated with pars planitis. Ophthalmology. 1993;100(6):818-824.

2. Woo SJ, Yu HG, Chung H. Surgical outcome of vitrectomy for macular hole secondary to uveitis. Acta Ophthalmol. 2010;88(7):e287-e288.

3. Shukla D, Dhawan A. Pharmacotherapeutic closure of a uveitic macular hole persisting after vitrectomy. Indian J Ophthalmol. 2011;59(4):335-336.

4. Georgalas I, Markomichelakis N, Ladas I. Retinal detachment due to a macular hole in a patient with Behçet disease treated with vitrectomy and silicone oil tamponade. Eur J Ophthalmol. 2008;18(6):1023-1024.

5. Al-Dhibi H, Abouammoh M, Al-Harthi E, et al. Macular hole in Behçet's disease. Indian J Ophthalmol. 2011;59(5):359-362.

6. Bonnin N, Cornut PL, Chaise F, et al. Spontaneous closure of macular holes secondary to posterior uveitis: case series and a literature review. J Ophthalmic Inflamm Infect. 2013;3(1):34

7. Hikichi T, Furukawa Y, Ohtsuka H, et al. Improvement of visual acuity one-year after vitreous surgery in eyes with residual triamcinolone acetonide at the macular hole. Am J Ophthalmol. 2008;145(2):267-272.

\section{Publish your work in this journal}

Therapeutics and Clinical Risk Management is an international, peerreviewed journal of clinical therapeutics and risk management, focusing on concise rapid reporting of clinical studies in all therapeutic areas, outcomes, safety, and programs for the effective, safe, and sustained use of medicines. This journal is indexed on PubMed Central, CAS,

\section{Dovepress}

EMBase, Scopus and the Elsevier Bibliographic databases. The manuscript management system is completely online and includes a very quick and fair peer-review system, which is all easy to use. Visit http://www.dovepress.com/testimonials.php to read real quotes from published authors. 